\title{
Effect of Lead Exposure on the Status of Reticulocyte Count Indices among Workers from Lead Battery Manufacturing Plant
}

\author{
Ravibabu Kalahasthi and Tapu Barman \\ Regional Occupational Health Centre (Southern), ICMR Complex, Pojanahalli Road, Devanahalli, Bangalore, India
}

(Received March 16, 2016; Revised May 18, 2016; Accepted June 1, 2016)

\begin{abstract}
Earlier studies conducted on lead-exposed workers have determined the reticulocyte count (RC) (\%), but the parameters of Absolute Reticulocyte Count (ARC), Reticulocyte Index (RI), and Reticulocyte Production Index (RPI) were not reported. This study assessed the effect of lead $(\mathrm{Pb})$ exposure on the status of reticulocyte count indices in workers occupied in lead battery plants. The present cross-sectional study was carried out on 391 male lead battery workers. The blood lead levels (BLL) were determined by using an Atomic Absorption Spectrophotometer. The RC (\%) was estimated by using the supravital staining method. The parameters, such as ARC, RI, and RPI, were calculated by using the RC (\%) with the red cell indices (RBC count and hematocrit). The levels of RBC count and hematocrit were determined by using an ABX Micros ES-60 hematology analyzer. The levels of reticulocyte count indices - RC (\%), ARC, RI, and RPI significantly increased with elevated BLL. The association between BLL and reticulocyte count indices was positive and significant. The results of linear multiple regression analysis showed that the reticulocyte count $(\beta=0.212, P<0.001)$, ARC $(\beta=0.217, P<0.001)$, RI $(\beta=0.194, P<0.001)$, and RPI $(\beta=0.208, P<0.001)$ were positively associated with BLL. The variable, smoking habits, showed a significant positive association with reticulocyte count indices: RC $(\%)(\beta=0.188, P<0.001)$, ARC $(\beta=$ $0.174, P<0.001)$, RI $(\beta=0.200, P<0.001)$, and RPI $(\beta=0.151, P<0.005)$. The study results revealed that lead exposure may cause reticulocytosis with an increase of reticulocyte count indices.
\end{abstract}

Key words: Blood lead levels, Reticulocyte count indices, Lead battery plant, Lifestyle factors

\section{INTRODUCTION}

Lead $(\mathrm{Pb})$ is used as a corrosion-resistant metal. It is a bluish-white metal used in construction, soldering, cable sheathing, and in manufacturing of lead batteries, pesticides, glass, paints and ammunition (1). More than threefourth of lead production is used for the manufacturing of lead batteries (2). Lead industries were considered hazardous as per the Indian Factories Act's first schedule under section 2 (cb) (3). The workers occupied in this process are exposed to $\mathrm{Pb}$ through inhalation and ingestion. The main targeted organs for $\mathrm{Pb}$ exposure are the brain, the blood forming system and the kidneys (4). Previous studies have

Correspondence to: Ravibabu Kalahasthi, Regional Occupational Health Centre (Southern), ICMR Complex, Pojanahalli Road, Devanahalli, Bangalore 562110, India

E-mail: kalahasthi20012002@yahoo.co.in

This is an Open-Access article distributed under the terms of the Creative Commons Attribution Non-Commercial License (http:// creativecommons.org/licenses/by-nc/3.0) which permits unrestricted non-commercial use, distribution, and reproduction in any medium, provided the original work is properly cited. reported high levels of oxidative stress (5), morbidities (69 ), biogenic amino acids and neurobehavioral functions (10), genotoxicity (11), decreased coagulation function (12), altered calcium metabolism indicating low bone-mineral density (13), toxic neuropathies (14), and dental erosion (15) among lead battery workers.

Immature red blood cells with the reticulum network of RNA and mitochondria are called reticulocyte, which is produced and matured in the bone marrow before being released into the blood. There are two types of reticulocyte such as aggregate and punctuate. The aggregate reticulocyte is larger in size and more immature with a coarsely clumped collection of reticulum; whereas, the punctuate reticulocyte is smaller in size and more mature with small sparse granules of residual RNA (16). The measurement of $\mathrm{RC}(\%)$ is used to classify anemia into regenerative (reticulocytosis) and non-regenerative (reticulocytopenia). In epidemiological studies, reticulocytosis is associated with cerebrovascular diseases (17) and iron-deficiency anemia (18); whereas, reticulocytopenia is associated with malaria (19) and parasitic infections (20). Studies regarding occupational exposure to $\mathrm{Pb}$ have a reported higher $\mathrm{RC}(\%)$ in 
workers from traditional tile factories (21), lead battery plants (22), acute lead-intoxicated battery plants (female workers) (23), battery repair shops (24) and shops manufacturing mixtures of talismanic ash (25). A high reticulocyte count was reported in the chronic $\mathrm{Pb}$ intoxicated animals $(26,27)$.

Anemia is accompanied with a high RC (\%) but does not reflect the bone marrow response in anemia. The parameters of ARC, reticulocyte index (RI) and reticulocyte production index (RPI) are essential to identify the bone marrow response in anemia. The RC (\%) was adjusted with the RBC count, and hematocrits, such as subjective hematocrit, normal hematocrit and hematocrit, with a maturation factor to attain ARC, RI and RPI, respectively (28). The assessment of RC (\%) was used to evaluate the degree of the erythropoiesis activity. The ARC and RI parameters were used to measure the RBC production and the degree of anemia caused either due to the loss of RBC or inadequate production of RBC. In lead-exposed workers, only RC (\%) was determined and other reticulocyte count indices, such as ARC, RI and RPI, were not assessed. Therefore, the present study was undertaken to investigate the effect of $\mathrm{Pb}$ exposure on the reticulocyte count indices such as RC (\%), ARC, RI \& RPI in workers who work in lead battery plants. Lifestyle factors were used as a mediating factors.

\section{MATERIALS AND METHODS}

This was cross-sectional study and investigations were carried out on 391 male subjects working in $\mathrm{Pb}$ battery plants located in Tamil Nadu, India. The status of reticulocyte count indices, such as RC (\%), ARC, RI and RPI, among lead-exposed workers were compared with age, Body Mass Index (BMI), experience, alcohol consumption, smoking habits, BLL and job category. The ethical committee of the institution has approved the present study. Subjects were informed about the purpose of the study and their consent was obtained before their participation.

Demographic details, occupational history and habits of subjects (smoking and alcohol consumption) were collected by using a pre-designed questionnaire. BMI was calculated using subjective weight $(\mathrm{Kg})$ and height $(\mathrm{m})$, and were expressed as $\mathrm{Kg} / \mathrm{m}^{2}$.

Blood lead levels. Three $\mathrm{ml}$ of venous whole blood was collected in a heparinized vacuette from the study subjects and was stored at $-20^{\circ} \mathrm{C}$ until the analysis. Using ETHOS-D, (Milestone Microwave Laboratory Systems, Sorisole, BG, Italy), $2 \mathrm{~mL}$ of whole blood was digested with $2 \mathrm{~mL}$ of nitric acid $\left(\mathrm{HNO}_{3}\right)$ and $0.2 \mathrm{~mL}$ of hydrogen peroxide $\left(\mathrm{H}_{2} \mathrm{O}_{2}\right)$ while maintaining power, temperature and duration of process. The digested samples were made up to $5 \mathrm{~mL}$ using distilled water and centrifuged. The concentration of lead was measured using Atomic Absorption Spec- trophotometer (GBC Avanta P, Dandenong, Victoria, Australia). A standard solution of $20 \mu \mathrm{g} / \mathrm{dL}$ of $\mathrm{Pb}$ was prepared from the stock standard solution obtained from the Merck (1.19776.0500) and added to the lowest concentration of the sample. The analysis found $100 \%$ recovery with $\%$ RSD at $<0.5$ for three replicates and the BLL was expressed as $\mu \mathrm{g} / \mathrm{dL}$.

\section{Reticulocyte count indices.}

Reticulocyte Count (RC) (\%): RC (\%) in peripheral blood samples was determined using the supravital staining method. In this method, equal volumes of stain were added to EDTA-anti-coagulant blood and the diluted blood was used to prepare the smear to examine the RC present in the sample. The RC in the sample was expressed as percentage. The manual method of reticulocyte count is reliable and cost-effective for estimating reticulocytes, in addition to competently determining the high and low ranges of RC (\%) (29).

Absolute Reticulocyte Count (ARC): $\mathrm{ARC}$ is a product of RC (\%) multiplied with RBC count. The RBC count was assessed by using an ABX Micros ES-60 hematology analyzer.

$$
\mathrm{ARC}=\mathrm{RC}(\%) \times \mathrm{RBC} \text { count }(\mathrm{mill} / \mu \mathrm{L}) \times 10 .
$$

Reticulocyte Index (RI): RI is a product of RC (\%) multiplied with subjective hematocrit and divided by normal hematocrit. The hematocrit was determined by using an ABX Micros ES-60 hematology analyzer.

$$
\mathrm{RI}=\mathrm{RC}(\%) \times \text { subjective hematocrit/normal hematocrit }
$$

Reticulocyte Production Index (RPI): RPI is a product of RI divided by the maturation factor. The maturation factor is represented by 1 day when hematocrit values are between 36 and $45 ; 1.5$ days, if hematocrit values are between 26 and 35; 2 days, if hematocrit values are between 16 and 25; and, 2.5 days, if hematocrit values are below 15 .

$$
\mathrm{RPI}=\mathrm{RI} / \text { maturation factor }
$$

Statistical analysis. Statistical Package for the Social Sciences (SPPS Inc., Chicago, USA) version 16 was used for the statistical analysis of the data. The data are presented in proportions and adjusted means with standard error. One-way Analysis of Variance (ANOVA) was used to assess the effects of categorical variables on $\mathrm{RC}$ indices. One-way ANOVA with post-hoc tests was used to compare various categories within the categorical variables on $\mathrm{RC}$ indices. The spearman correlation coefficient test was used to evaluate the association between BLL and reticulocyte count indices. Multiple linear regression analysis was used to evaluate the association between reticulocyte count indices and BLL by controlling the influence of age, BMI, 
smoking habits, alcohol consumption and experience. Probability $(p)$ value less than 0.05 was considered significant.

\section{RESULTS}

Demographic characteristics of the subjects are presented in Table 1. The age distribution indicated that maximum number of workers was in the age group of 33 38 years and minimum was in the age group of 21 26 years. The BMI of the subjects revealed that $54.2 \%$ had normal BMI, $41.2 \%$ were overweight, $3.8 \%$ were obese and only $0.8 \%$ were underweight. A majority of the workers had more than thirteen years of lead exposure. Alcohol consumption and

Table 1. Demographic characteristics of lead exposed workers

\begin{tabular}{|c|c|c|}
\hline Variables & N (391) & Percentage $(\%)$ \\
\hline \multicolumn{3}{|l|}{ Age (years) } \\
\hline $21 \sim 26$ & 18 & 4.6 \\
\hline $27 \sim 32$ & 91 & 23.3 \\
\hline $33 \sim 38$ & 233 & 59.6 \\
\hline$\geq 39$ & 49 & 12.5 \\
\hline \multicolumn{3}{|l|}{ BMI $\left(\mathrm{Kg} / \mathrm{m}^{2}\right)$} \\
\hline$\leq 18.5$ & 3 & 0.8 \\
\hline $18.5 \sim 24.9$ & 212 & 54.2 \\
\hline $25 \sim 29.9$ & 161 & 41.2 \\
\hline$\geq 30$ & 15 & 3.8 \\
\hline \multicolumn{3}{|l|}{ Experience (years) } \\
\hline$\leq 4$ & 19 & 4.9 \\
\hline $5 \sim 8$ & 54 & 13.8 \\
\hline $9 \sim 12$ & 114 & 29.2 \\
\hline$\geq 13$ & 204 & 52.2 \\
\hline \multicolumn{3}{|l|}{ Alcohol consumption } \\
\hline No & 246 & 62.9 \\
\hline Yes & 145 & 37.1 \\
\hline \multicolumn{3}{|l|}{ Smoking } \\
\hline No & 315 & 80.6 \\
\hline Yes & 76 & 19.4 \\
\hline \multicolumn{3}{|l|}{$\mathrm{BLL}(\mu \mathrm{g} / \mathrm{dL})$} \\
\hline$\leq 20$ & 137 & 35.0 \\
\hline $21 \sim 30$ & 110 & 28.1 \\
\hline $31 \sim 40$ & 81 & 20.7 \\
\hline $41 \sim 50$ & 49 & 12.5 \\
\hline$\geq 51$ & 14 & 3.6 \\
\hline \multicolumn{3}{|l|}{ Job categories } \\
\hline Assembly & 208 & 53.2 \\
\hline Casting & 46 & 11.8 \\
\hline Pasting & 41 & 10.5 \\
\hline Ball mill & 9 & 2.3 \\
\hline Charging & 25 & 6.4 \\
\hline Plate cutting & 4 & 1.0 \\
\hline Formation & 8 & 2.0 \\
\hline Acid filling & 7 & 1.8 \\
\hline Engineer services & 33 & 8.4 \\
\hline Other workers & 10 & 2.6 \\
\hline
\end{tabular}

smoking habits were recorded in $37.1 \%$ and $19.4 \%$ of the subjects, respectively. The frequency distribution of BLL among the subjects was $35 \%, 28.1 \%, 20.7 \%, 12.5 \%$ and $3.5 \%$ in $\leq 20,21 \sim 30,31 \sim 40,41 \sim 50$ and $>51 \mu \mathrm{g} / \mathrm{dL}$, respectively.

The univariate analysis of variables that affect the reticulocyte count indices among lead-exposed workers are presented in Table 2. ANOVA was used to find out the effects of categorical variables, - such as age, BMI, experience, alcohol consumption, smoking habits, BLL and job category, - on reticulocyte count indices among lead-exposed workers. The results of the model indicated that the BLL and smoking habits were significantly associated with $\mathrm{RC}$ $(\%), A R C, R I$ and RPI. The One-way ANOVA with the post-hoc comparison method was used to evaluate the effects of various categories within the categorical variables on the status of reticulocyte count indices. The reticulocyte count indices, such as RC, RI and RPI, were significantly high in BLL categories, namely $21 \sim 30$ and $41 \sim 50$, and $>51 \mu \mathrm{g} / \mathrm{dL}$ in contrast to $\leq 20 \mu \mathrm{g} / \mathrm{dL}$. Age, BMI, experience and job category did not have significant effect on reticulocyte count indices.

The results of Spearmen's correlation coefficients (r) between BLL and reticulocyte count indices among leadexposed workers are presented in Table 3. A positive and significant correlation coefficient was noticed between BLL and reticulocyte indices such as RC $(\%)(\mathrm{r}=0.233)$, ARC $(r=0.232)$, RI $(r=0.227)$ and RPI $(r=0.227)$. Similarly, the association between RC (\%) and ARC ( $\mathrm{r}=0.950)$, RI $(\mathrm{r}=0.958)$ and RPI $(\mathrm{r}=0.886)$ was positive and significant. The correlation coefficient between ARC and RI ( $\mathrm{r}=$ $0.954)$, RPI $(r=0.849)$ and $\mathrm{RC}(\mathrm{r}=0.886)$ was positive and significant. The association between RPI and RI, ARC and $\mathrm{RC}$ was also found to be positive and significant.

Linear multiple regression analysis of variables that affect the reticulocyte indices among lead-exposed workers are presented in Table 4. In this model, each of the parameters of the reticulocyte count indices such as RC (\%), ARC, RI and RPI were used as dependent variables, and factors such as BLL, age, BMI, smoking habits (yes $=1$ and no $=0$ ), alcohol consumption (yes $=1$ and no $=0$ ) and experience (years) were used as independent variables. The results of linear multiple regression analysis showed that the RC (\%), $\mathrm{ARC}, \mathrm{RI}$ and RPI were positively related with BLL and smoking habits. Age, alcohol consumption and BMI were not significantly related to the reticulocyte count indices.

\section{DISCUSSION}

Earlier studies on lead-exposed workers have reported that RC (\%) and other indices such as ARC, RI and RPI are not studied. These parameters are essential to identify the bone marrow response in anemia. The present study assessed the effects of lead exposure on reticulocyte count indices in 
Table 2. Univariate analysis of the variables that affect reticulocyte indices among lead exposed workers

\begin{tabular}{|c|c|c|c|c|c|c|}
\hline Variables & N (391) & Percentage (\%) & $\mathrm{RC}$ & $\mathrm{ARC}$ & RI & RPI \\
\hline \multicolumn{7}{|l|}{ Age (years) } \\
\hline $21 \sim 26$ & 18 & 4.6 & $0.99 \pm 0.07$ & $53.94 \pm 4.29$ & $1.02 \pm 0.08$ & $1.02 \pm 0.08$ \\
\hline $27 \sim 32$ & 91 & 23.3 & $1.07 \pm 0.03$ & $56.53 \pm 1.71$ & $1.07 \pm 0.03$ & $1.13 \pm 0.03$ \\
\hline $33 \sim 38$ & 233 & 59.6 & $1.03 \pm 0.02$ & $55.45 \pm 1.12$ & $1.03 \pm 0.02$ & $1.09 \pm 0.02$ \\
\hline$\geq 39$ & 49 & 12.5 & $1.00 \pm 0.04$ & $53.91 \pm 2.33$ & $0.99 \pm 0.04$ & $1.07 \pm 0.05$ \\
\hline$P$ values for ANOVA test & & & $P=0.584$ & $P=0.821$ & $P=0.590$ & $P=0.588$ \\
\hline \multicolumn{7}{|l|}{ BMI $\left(\mathrm{Kg} / \mathrm{m}^{2}\right)$} \\
\hline$\leq 18.5$ & 3 & 0.8 & $0.86 \pm 0.29$ & $48.00 \pm 17.05$ & $0.90 \pm 0.32$ & $0.96 \pm 0.26$ \\
\hline $18.5 \sim 24.9$ & 212 & 54.2 & $1.02 \pm 0.02$ & $54.93 \pm 1.13$ & $1.02 \pm 0.02$ & $1.09 \pm 0.02$ \\
\hline $25 \sim 29.9$ & 161 & 41.2 & $1.05 \pm 0.02$ & $55.95 \pm 1.36$ & $1.05 \pm 0.02$ & $1.10 \pm 0.02$ \\
\hline$\geq 30$ & 15 & 3.8 & $1.11 \pm 0.07$ & $58.66 \pm 3.74$ & $1.12 \pm 0.07$ & $1.15 \pm 0.07$ \\
\hline$P$ values for ANOVA test & & & $P=0.435$ & $P=0.693$ & $P=0.521$ & $P=0.849$ \\
\hline \multicolumn{7}{|l|}{ Experience (years) } \\
\hline$\leq 4$ & 19 & 4.9 & $1.13 \pm 0.07$ & $60.57 \pm 3.94$ & $1.15 \pm 0.07$ & $1.15 \pm 0.07$ \\
\hline $5 \sim 8$ & 54 & 13.8 & $1.02 \pm 0.04$ & $55.64 \pm 2.29$ & $1.04 \pm 0.04$ & $1.15 \pm 0.05$ \\
\hline $9 \sim 12$ & 114 & 29.2 & $1.02 \pm 0.02$ & $54.07 \pm 1.53$ & $1.01 \pm 0.03$ & $1.05 \pm 0.03$ \\
\hline$\geq 13$ & 204 & 52.2 & $1.04 \pm 0.02$ & $55.67 \pm 1.20$ & $1.04 \pm 0.02$ & $1.10 \pm 0.02$ \\
\hline$P$ values for ANOVA test & & & $P=0.493$ & $P=0.468$ & $P=0.350$ & $P=0.258$ \\
\hline \multicolumn{7}{|l|}{ Alcohol consumed } \\
\hline No & 246 & 62.9 & $1.03 \pm 0.02$ & $55.26 \pm 1.03$ & $1.03 \pm 0.02$ & $1.09 \pm 0.02$ \\
\hline Yes & 145 & 37.1 & $1.04 \pm 0.03$ & $55.74 \pm 1.49$ & $1.05 \pm 0.02$ & $1.10 \pm 0.03$ \\
\hline$P$ values for ANOVA test & & & $P=0.945$ & $P=0.786$ & $P=0.604$ & $P=0.719$ \\
\hline \multicolumn{7}{|l|}{ Smoking } \\
\hline No & 315 & 80.6 & $1.01 \pm 0.01$ & $54.02 \pm 0.93$ & $1.00 \pm 0.02$ & $1.07 \pm 0.02$ \\
\hline Yes & 76 & 19.4 & $1.15 \pm 0.03^{*}$ & $61.31 \pm 1.96^{*}$ & $1.16 \pm 0.03^{*}$ & $1.20 \pm 0.03^{*}$ \\
\hline$P$ values for ANOVA test & & & $P<0.001$ & $P<0.001$ & $P<0.001$ & $P<0.005$ \\
\hline \multicolumn{7}{|l|}{$\mathrm{BLL}(\mu \mathrm{g} / \mathrm{dL})$} \\
\hline$\leq 20$ & 137 & 35.0 & $0.96 \pm 0.02$ & $51.36 \pm 1.38$ & $0.96 \pm 0.02$ & $1.02 \pm 0.02$ \\
\hline $21 \sim 30$ & 110 & 28.1 & $1.06 \pm 0.03^{*}$ & $56.98 \pm 1.56^{*}$ & $1.06 \pm 0.03^{*}$ & $1.12 \pm 0.03^{*}$ \\
\hline $31 \sim 40$ & 81 & 20.7 & $1.04 \pm 0.03$ & $55.22 \pm 2.00$ & $1.03 \pm 0.03$ & $1.11 \pm 0.04$ \\
\hline $41 \sim 50$ & 49 & 12.5 & $1.10 \pm 0.03^{*}$ & $60.08 \pm 2.22^{*}$ & $1.12 \pm 0.04^{*}$ & $1.18 \pm 0.04^{*}$ \\
\hline$\geq 51$ & 14 & 3.6 & $1.27 \pm 0.07^{*}$ & $68.28 \pm 3.70^{*}$ & $1.26 \pm 0.06^{*}$ & $1.35 \pm 0.11^{*}$ \\
\hline$P$ values for ANOVA test & & & $P<0.005$ & $P<0.001$ & $P<0.005$ & $P<0.005$ \\
\hline \multicolumn{7}{|l|}{ Job category } \\
\hline Assembly & 208 & 53.2 & $1.06 \pm 0.02$ & $56.95 \pm 1.15$ & $1.06 \pm 0.02$ & $1.13 \pm 0.02$ \\
\hline Casting & 46 & 11.8 & $1.02 \pm 0.04$ & $54.19 \pm 2.32$ & $1.01 \pm 0.04$ & $1.04 \pm 0.04$ \\
\hline Pasting & 41 & 10.5 & $1.02 \pm 0.05$ & $52.78 \pm 2.63$ & $1.01 \pm 0.05$ & $1.07 \pm 0.05$ \\
\hline Ball mill & 9 & 2.3 & $1.20 \pm 0.10$ & $63.66 \pm 5.75$ & $1.18 \pm 0.10$ & $1.28 \pm 0.10$ \\
\hline Charging & 25 & 6.4 & $0.98 \pm 0.06$ & $52.40 \pm 3.65$ & $0.98 \pm 0.07$ & $1.07 \pm 0.07$ \\
\hline Plate cutting & 4 & 1.0 & $1.07 \pm 0.07$ & $58.00 \pm 3.46$ & $1.12 \pm 0.06$ & $1.12 \pm 0.06$ \\
\hline Formation & 8 & 2.0 & $0.92 \pm 0.11$ & $48.87 \pm 6.63$ & $0.90 \pm 0.12$ & $0.96 \pm 0.11$ \\
\hline Acid filling & 7 & 1.8 & $0.95 \pm 0.06$ & $49.71 \pm 3.61$ & $0.94 \pm 0.06$ & $1.04 \pm 0.08$ \\
\hline Engineer services & 33 & 8.4 & $0.98 \pm 0.06$ & $53.06 \pm 3.38$ & $0.99 \pm 0.06$ & $1.02 \pm 0.06$ \\
\hline Misc & 10 & 2.6 & $1.02 \pm 0.09$ & $56.90 \pm 5.64$ & $1.03 \pm 0.10$ & $1.15 \pm 0.12$ \\
\hline$P$ values for ANOVA test & & & $P=0.614$ & $P=0.465$ & $P=0.572$ & $P=0.444$ \\
\hline
\end{tabular}

Values are mean \pm standard error. ${ }^{*}$ Indicate $P<0.05$ and significant.

lead-exposed workers. Infant aged 27 months are reported to have higher RC (\%)than a one-year old (30). People above 60 years are reported to have low RC (\%) than the young, healthy adults (31). However, the findings of this study, i.e., both univariate and regression analyzes, observed no significant association between reticulocyte count indi- 
Table 3. Spearmen correlation coefficient $(r)$ between blood lead levels and reticulocyte count indices among lead exposed workers

\begin{tabular}{lccccc}
\hline \hline Parameters & $\begin{array}{c}\text { BLL } \\
(\mu \mathrm{g} / \mathrm{dL})\end{array}$ & $\begin{array}{c}\text { Reticulocyte } \\
\text { count }(\%)\end{array}$ & $\begin{array}{c}\text { Absolute reticulocyte } \\
\text { count }\left(\times 10^{9} / \mathrm{L}\right)\end{array}$ & $\begin{array}{c}\text { Reticulocyte } \\
\text { index }(\%)\end{array}$ & $\begin{array}{c}\text { Reticulocyte production } \\
\text { index }(\%)\end{array}$ \\
\hline BLLs $(\mu \mathrm{g} / \mathrm{dL})$ & 1.000 & - & - & - & - \\
Reticulocyte count $(\%)$ & $0.233^{* *}$ & 1.000 & - & - & - \\
Absolute reticulocyte count $\left(\times 10^{9} / \mathrm{L}\right)$ & $0.232^{* *}$ & $0.950^{* * *}$ & 1.000 & - & - \\
Reticulocyte index $(\%)$ & $0.227^{* *}$ & $0.958^{* * *}$ & $0.954^{* *}$ & 1.000 & - \\
Reticulocyte production index $(\%)$ & $0.227^{* *}$ & $0.886^{* *}$ & $0.849^{* *}$ & $0.852^{* *}$ & 1.000 \\
\hline
\end{tabular}

${ }^{*}$ Correlation is coefficient significant at $P<0.001$.

Table 4. Linear multiple regression analysis of variables that affect on reticulocyte count indices among lead exposed workers

\begin{tabular}{lcccc}
\hline \hline Independent variables & $\begin{array}{c}\text { Reticulocyte } \\
\text { count }(\%)\end{array}$ & $\begin{array}{c}\text { Absolute reticulocyte } \\
\text { count }\left(\times 10^{9} / \mathrm{L}\right)\end{array}$ & $\begin{array}{c}\text { Reticulocyte } \\
\text { index (\%) }\end{array}$ & $\begin{array}{c}\text { Reticulocyte production } \\
\text { index (\%) }\end{array}$ \\
\hline Age (years) & -0.004 & -0.004 & -0.030 & 0.029 \\
Body mass index $\left(\mathrm{Kg} / \mathrm{m}^{2}\right)$ & 0.036 & 0.029 & 0.039 & 0.000 \\
Blood lead levels $(\mu \mathrm{g} / \mathrm{dL})$ & $0.212^{* *}$ & $0.217^{* *}$ & $0.194^{* *}$ & $0.208^{* *}$ \\
Duration of exposure (years) & 0.009 & 0.014 & 0.006 & -0.002 \\
Alcohol consumption & -0.084 & -0.070 & -0.064 & -0.053 \\
Smoking & $0.188^{* *}$ & $0.174^{*}$ & $0.200^{* * *}$ & $0.151^{*}$ \\
\hline
\end{tabular}

Linear multiple regression model included age, BMI, Blood lead levels, duration of exposure (years), alcohol consumption and smoking. Standardized regression coefficient $\beta$ is significant ${ }^{*} P<0.05$ and ${ }^{* *} P<0.001$.

ces and age groups. A reduced BMI was associated with decreased RC (\%) and RPI (32). In this study, both univariate and regression analyzes showed positive and no significant association between reticulocyte count indices and BMI. Earlier studies report high levels of hematocrit and $\mathrm{RC}(\%)$ in smokers as compared to non-smokers (33). Smoking is also associated with high levels of hemoglobin $(\mathrm{Hb} \%)$, RBC count and hematocrit (34). In this study, a positive and significant association between the smoking habit and reticulocyte count indices were found.

Anemia in alcoholics may be due to multiple factors such as poor nutrition, prolonged inflammation, blood loss, liver dysfunction and ineffective erythropoiesis (35). About 37\% of chronic alcoholics were reported with reticulocytosis (36). In the present study, the reticulocyte count indices showed no significant difference between the group that consumed alcohol and the group that did not consume alcohol. The pattern of occasional alcohol consumption was also observed among the study subjects.

High levels of RC (\%) with low levels of $\mathrm{Hb} \%$, hematocrit and RBC count were observed in populations exposed to lead from cooking utensils, indigenous medicinal powder (37), lead poisoning cases (38) and lead batteries (23). The literature reports a positive and significant association $(>30 \mu \mathrm{g} / \mathrm{dL})$ between BLL and RC (\%) in lead battery workers (22). In the current study, the correlation coefficient between BLL and the reticulocyte count indices (RC, $\mathrm{ARC}, \mathrm{RI}$ and RPI) was found to be positive and significant. Lead exposure has been associated with induced anemia due to short lifespan of erythrocytes, inhibition of hemoglo- bin synthesis, reduction of erythroid progenitor cells and inappropriate erythropoietin production (39). The association between BLL and erythropoietin concentration was reported to be negative (40). $\mathrm{Pb}$ exposure on human $\mathrm{RBC}$ could increase micro-vesicle generation and hemolysis (41), the severity of which is positively associated with reticulocyte count (42). The result of the study shows that the BLL and smoking habits have a significant effect on the reticulocyte count indices (RC, ARC, RI and RPI) among leadexposed workers. The variables of age, BMI, experience, alcohol consumption and job category did not predict any significant association with reticulocyte count indices. The results of the study indicate that $\mathrm{Pb}$ exposure may cause reticulocytosis with increased reticulocyte count indices.

\section{REFERENCES}

1. Tong, S., von Schirnding, Y.E. and Prapamontol, T. (2000) Environmental lead exposure: a public health problem of global dimensions. Bull. World Health Organ., 78, 1068-1077.

2. Van der Kuijp, T.J., Huang, L. and Cherry, C.R. (2013) Health hazards of China's lead-acid battery industry: a review of its market drivers, production processes, and health impacts. Environ. Health, 12, 61.

3. Indian Factories Act. (1948) List of Industries involving hazardous processes as defined U/s 2(cb). Available from: http:// www.karmayog.org/childlabour/childlabour_17879.htm/.

4. Agency for Toxic Substances and Diseases Registry (2010) Toxicological profile for lead. U.S. department of health and human services, Public Health Service, Atlanta.

5. Ghanwat, G.H., Patil, A.J., Patil, J.A., Kshirsagar, M.S., Son- 
takke, A. and Ayachit, R.K. (2016) Biochemical effects of lead exposure on oxidative stress and antioxidant status of battery manufacturing workers of Western Maharashtra, India. $J$. Basic Clin. Physiol. Pharmacol., 27, 141-146.

6. Basit, S., Karim, N. and Munshi, A.B. (2015) Occupational lead toxicity in battery workers. Pak. J. Med. Sci., 31, 775780.

7. Ahmad, S.A., Khan, M.H., Khandker, S., Sarwar, A.F., Yasmin, N., Faruquee, M.H. and Yasmin, R. (2014) Blood lead levels and health problems of lead acid battery workers in Bangladesh. Sci. World J., 2014, 974104.

8. Kalahasthi, R.B., Barman, T. and Rajmohan, H.R. (2014) The relationship between blood lead levels and morbidities among workers employed in a factory manufacturing lead-acid storage battery. Int. J. Environ. Health Res., 24, 246-255.

9. Rapisarda, V., Ledda, C., Ferrante, M., Fiore, M., Cocuzza, S., Bracci, M. and Fenga, C. (2015) Blood pressure and occupational exposure to noise and lead $(\mathrm{Pb})$ : across-sectional study. Toxicol. Ind. Health., pii: 0748233715576616 [Epub ahead of print].

10. Ravibabu, K., Barman, T. and Rajmohan, H.R. (2015) Serum neuron-specific enolase, biogenic amino-acids and neurobehavioral function in lead-exposed workers from lead-acid battery manufacturing process. Int. J. Occup. Environ. Med., 6, 50-57.

11. Chinde, S., Kumari, M., Devi, K.R., Murty, U.S., Rahman, M.F., Kumari, S.I., Mahboob, M. and Grover, P. (2014) Assessment of genotoxic effects of lead in occupationally exposed workers. Environ. Sci. Pollut. Res. Int., 21, 1146911480.

12. Barman, T., Kalahasthi, R. and Rajmohan, H.R. (2014) Effects of lead exposure on the status of platelet indices in workers involved in a lead-acid battery manufacturing plant. J. Expo. Sci. Environ. Epidemiol., 24, 629-633.

13. Dongre, N.N., Suryakar, A.N., Patil, A.J., Hundekari, I.A. and Devarnavadagi, B.B. (2013) Biochemical effects of lead exposure on battery manufacture workers with reference to blood pressure, calcium metabolism and bone mineral density. Indian J. Clin. Biochem., 28, 65-70.

14. Misra, U.K. and Kalita, J. (2009) Toxic neuropathies. Neurol. India, 57, 697-705.

15. Suyama, Y., Takaku, S., Okawa, Y. and Matsukubo, T. (2010) Dental erosion in workers exposed to sulfuric acid in lead storage battery manufacturing facility. Bull. Tokyo Dent. Coll., 51, 77-83.

16. Cowgill, E.S., Neel, J.A. and Grindem, C.B. (2003) Clinical application of reticulocyte counts in dogs and cats. Vet. Clin. North Am. Small Anim. Pract., 33, 1223-1244.

17. Silva, C.M., Giovani, P. and Viana, M.B. (2011) High reticulocyte count is an independent risk factor for cerebrovascular disease in children with sickle cell anemia. Pediatr. Blood Cancer, 56, 116-121.

18. Ceylan, C., Miskioglu, M., Colak, H., Kiliccioglu, B. and Ozdemir, E. (2007) Evaluation of reticulocyte parameters in iron deficiency, vitamin $\mathrm{B}(12)$ deficiency and beta-thalassemia minor patients. Int. J. Lab. Hematol., 29, 327-334.

19. Leowattana, W., Krudsood, S., Tangpukdee, N., Brittenham, G. and Looareesuwan, S. (2008) Defective erythropoietin production and reticulocyte response in acute Plasmodium falci- parum malaria-associated anemia. Southeast Asian J. Trop. Med. Public Health, 39, 581-588.

20. Degarege, A. and Erko, B. (2016) Epidemiology of plasmodium and helminth coinfection and possible reasons for heterogeneity. BioMed Res. Int., 2016, 3083568.

21. Balali-Mood, M., Shademanfar, S., Rastegar Moghadam, J., Afshari, R., Namaei Ghassemi, M., Allah Nemati, H., Keramati, M.R., Neghabian, J., Balali-Mood, B. and Zare, G. (2010) Occupational lead poisoning in workers of traditional tile factories in Mashhad, Northeast of Iran. Int. J. Occup. Environ. Med., 1, 29-38.

22. Kalahasthi, R., Barman, T. and Rao, H.R. (2012) Assessment of the relationship between blood lead levels and hematological parameters among lead acid-storage battery plant workers. J. Environ. Occup. Sci., 1, 1-5.

23. Dounias, G., Rachiotis, G. and Hadjichristodoulou, C. (2010) Case report: acute lead intoxication in a female battery worker: diagnosis and management. J. Occup. Med. Toxicol., $5,19$.

24. Bashir, F.Y. and Al-Ameen, A.M. (2008) Effects of direct exposure to lead on some hematological parameters among battery repair workers in Mosul. Ann. Coll. Med. Mosul., 34, 58-63.

25. Ye, H.H., Jeong, J.U., Baek, N.J., Choi, C.Y., Jeon, M.J. and Sakong, J. (2013) A case of lead poisoning due to a mixture of talisman ash. Ann. Occup. Environ. Med., 25, 37.

26. Panov, V.G., Katsnelson, B.A., Varaksin, A.N., Privalova, L.I., Kireyeva, E.P., Sutunkova, M.P., Valamina, I.E. and Beresneva, O.Y. (2015) Further development of mathematical description for combined toxicity: a case study of lead-fluoride combination. Toxicol. Rep., 2, 297-307.

27. Alqayim, M.A.J. and Asis, S.A. (2013) Protective role of vita$\min \mathrm{E}$ and/or methionine against lead- induce changes on hematological parameters in rabbits. Iraqi J. Med. Sci., 11, 187-194.

28. Szigeti, R.G. and Curry, G.V. Reticulocyte count and reticulocyte hemoglobin content: Reference Range, Interpretation, Collection and Panels. Available from: http://emedicine.medscape.com/article/2086146-overview/[Updated Sep 05, 2014].

29. Ali, A., Moiz, B. and Omer, S. (2010) Is manual reticulocyte count a reliable option for under resourced countries. J. Pak. Med. Assoc., 60, 892-896.

30. Bukhari, K.T. and Zafar, H. (2013) Reference values of reticulocyte counts in five age groups of healthy infants at Rawalpindi, Pakistan. J. Pak. Med. Assoc., 63, 1108-1111.

31. Jain, P., Jain, P., Shah, C., Jindal, M., Jain, A.K. and Dixit, R. (2013) A comparative study of reticulocyte count in healthy young adult and dlderly age group subjects. NJIRM, 4, 118122.

32. Santos, J., Salgado, P., Santos, C., Mendes, P., Saavedra, J., Baldaque, P., Monteiro, L. and Costa, E. (2014) Effect of bariatric surgery on weight loss, inflammation, iron metabolism, and lipid profile. Scand. J. Surg., 103, 21-25.

33. Ugbebor, O.U., Oseni, B.A., Arinolas, O.G., Osazuwa, F., Zabayo, O.J., Dirisu, J.O., Aberare, L.O., Okuonghae, P.E. and Ibadin, E.E. (2011) Red blood cell susceptibility to oxidants in chronic cigarette smokers. Res. J. Pharm. Biol. Chem. Sci., 2, 380-388.

34. Asif, M., Karim, S., Umar, Z., Malik, A., Ismail, T., Chaud- 
hary, A., Al-Qahtani, M. and Rasool, M. (2013) Effect of cigarette smoking based on hematological parameters: comparison between male smokers and nonsmokers. Turk. J. Biochem., 38, 75-80.

35. Lewis, G., Wise, M.P., Poynton, C. and Godkin, A. (2007) A case of persistent anemia and alcohol abuse. Nat. Clin. Pract. Gastroenterol. Hepatol., 4, 521-526.

36. Latvala, J., Parkkila, S. and Niemela, O. (2004) Excess alcohol consumption is common in patients with cytopenia: studies in blood and bone marrow cells. Alcohol. Clin. Exp. Res., 28, 619-624.

37. Rolston, D.D.K. (2011) Uncommon sources and some unusual manifestations of lead poisoning in a tropical developing country. Trop. Med. Health, 39, 127-132.

38. Kadu, A.S., Nampalliwar, A.R., Pandey, A.G., Sharma, A. and Gothecha, V.K. (2012) Lead poisoning: an overlooked diagnosis in clinical practice. IJRAP, 3, 639-644.

39. Osterode, W., Barnas, U. and Geissler, K. (1999) Dose dependent reduction of erythroid progenitor cells and inappropriate erythropoietin response in exposure to lead: new aspects of anemia induced by lead. Occup. Environ. Med., 56, 106-109.

40. Liebelt, E.L., Schonfeld, D.J. and Gallagher, P. (1999) Elevated blood lead levels in children are associated with lower erythropoietin concentrations. J. Pediatr, 134, 107-109.

41. Kim, K.Y., Lim, K.M., Shin, J.H., Noh, J.Y., Ahn, J.B., Lee, D.H. and Chung, J.H. (2009) Effect of lead (IV) acetate on procoagulant activity in human red blood cells. Toxicol. Res., 25, $175-180$

42. Nouraie, M., Lee, J.S., Zhang, Y., Kanias, T., Zhao, X., Xiong, Z., Oriss, T.B., Zeng, Q., Kato, G.J., Gibbs, J.S., Hildesheim, M.E., Sachdev, V., Barst, R.J., Machado, R.F., Hassell, K.L., Little, J.A., Schraufnagel, D.E., Krishnamurti, L., Novelli, E., Girgis, R.E., Morris, C.R., Rosenzweig, E.B., Badesch, D.B., Lanzkron, S., Castro, O.L., Goldsmith, J.C., Gordeuk, V.R. and Gladwin, M.T. (2013). The relationship between the severity of hemolysis, clinical manifestations and risk of death in 415 patients with sickle cell anemia in the US and Europe. Haematologica, 98, 464-472. 